\title{
Information presentation and troubleshooting in electrical circuits
}

Citation for published version (APA):

Kester, L., Kirschner, P. A., \& Van Merriënboer, J. (2004). Information presentation and troubleshooting in electrical circuits. International Journal of Science Education, 26(2), 239-256.

https://doi.org/10.1080/69032000072809

DOI:

$10.1080 / 69032000072809$

Document status and date:

Published: 01/01/2004

Document Version:

Early version, also known as pre-print

Please check the document version of this publication:

- A submitted manuscript is the version of the article upon submission and before peer-review. There can be important differences between the submitted version and the official published version of record. People interested in the research are advised to contact the author for the final version of the publication, or visit the DOI to the publisher's website.

- The final author version and the galley proof are versions of the publication after peer review.

- The final published version features the final layout of the paper including the volume, issue and page numbers.

Link to publication

\section{General rights}

Copyright and moral rights for the publications made accessible in the public portal are retained by the authors and/or other copyright owners and it is a condition of accessing publications that users recognise and abide by the legal requirements associated with these rights.

- Users may download and print one copy of any publication from the public portal for the purpose of private study or research.

- You may not further distribute the material or use it for any profit-making activity or commercial gain

- You may freely distribute the URL identifying the publication in the public portal.

If the publication is distributed under the terms of Article 25fa of the Dutch Copyright Act, indicated by the "Taverne" license above, please follow below link for the End User Agreement:

https://www.ou.nl/taverne-agreement

Take down policy

If you believe that this document breaches copyright please contact us at:

pure-support@ou.nl

providing details and we will investigate your claim.

Downloaded from https://research.ou.nl/ on date: 26 Apr. 2023 
This is a pre-print of the article that was published as:

Kester, L., Kirschner, P.A., \& Van Merriënboer, J.J.G. (2004). Information presentation and troubleshooting in electrical circuits. International Journal of Science Education, 26, 239-256.

Copyright Taylor and Francis, available online at http://www.tandf.co.uk/journals/titles/09500693.asp

INFORMATION PRESENTATION AND TROUBLESHOOTING IN ELECTRICAL CIRCUITS

Liesbeth Kester (Email: liesbeth.kester@ou.nl),Paul A. Kirschner, Jeroen J. G. van Merriënboer, Educational Technology Expertise Centre, Open University of the Netherlands, Heerlen, The Netherlands 
While learning a complex skill in science using a computer-based simulation, optimal timing of information presentation facilitates learning and enhances test performance. An optimal information presentation format is proposed: supportive information is presented before practicing a skill and procedural information is presented during practice. Four information presentation formats were compared in a factorial design with the factors timing of supportive information (before or during task practice) and timing of procedural information (before or during task practice). Eighty-eight third year high school students (37 male, 51 female; mean age $=14$ years, $\underline{\text { SD }}$ $=0.52)$ participated in the experiment. Information searching behaviour and transfer test performance were studied. The information searching behaviour confirms the hypothesis. Findings on the transfer test are less clear due to a bottom effect. 


\section{Introduction}

Since the industrial revolution, Western society has focused on 'improvement'. A lot of money, time and effort has been spent on the optimalisation and innovation of technologies and production processes in industry, medicine, education, and so forth. In the seventies, this drive for increasing effectiveness and efficiency led to a revolution in inventory management. A new concept was introduced which radically changed the way Japanese and, later, American, manufacturers handled their stock. Instead of the traditional just-in-case (JIC) inventory systems based on long production runs, stockpiled inventories and uninterrupted production, a just-in-time (JIT) inventory system was introduced (Hoyt, 1996). The key concept behind this kind of inventory management is demand-pull production; the demand for a certain product determines when production should occur. This allows a manufacturer to produce only what is needed, in the appropriate quantity and at the right time. In this way, the stockpiling of unnecessary inventory is prevented because only inventory that is required by the demand-pull is held in stock (Cheng and Podolsky, 1993).

It is not only the business production processes that are put under pressure by the urge to improve, but also the performance levels of new recruits and existing staff are a continuing concern (Fuchsberg, 1990). Rapidly changing technologies and market conditions require lifelong, continuous, learning by employees. In order to make this continuous learning process more effective and efficient traditional classroom approaches are being abandoned (Openworld, 2000) in favour of learning on demand or 'just-in-time learning'. In this type of learning the demand-pull principle used to improve the production process is applied to business education. By applying this principle, the time lag that often exists between the complex skills or knowledge that a business requires and the education that must be provided for its acquisition, is reduced (Hoyt, 1996). The business' demand for complex skills and knowledge is used to signal when employee training should occur. Specific business courses 
are provided just before employees need the complex skills or knowledge at work. Next to specialized training agencies, higher education institutions are becoming more involved in delivering this post-secondary education and training. Curricula are modularised and developed for non-traditional, work-based subject matter while improvements in technology make virtual delivery of course material possible and allow for increased flexibility, convenience, interactivity and customisation of this material (Gallagher, 2001).

Improving the training content itself can further enhance effectiveness and efficiency of education in life-long learning, which starts in nursery school. Not only should the training be just in time, but also, to optimise the learning process within the training, the necessary information to acquire the complex skill or knowledge should be presented at the right time within the training itself. Again, the demand-pull principle is applied outside its original context. The demand for specific information, resulting from task requirements, is used to signal when this information should be presented during the training. It is argued that the learning of a complex skill requires different types of information and that, for increasing the effectiveness and efficiency of the training, each type has to be presented at different times during the training. Advances in technology make it possible to develop computer-based learning environments in which it is possible to easily vary the timing of information presentation (e.g. on-line help systems, pop-up balloons, use of hyperlinks, and so forth). These technological advances are of special importance in science education.

Practicals play a prominent and costly role- both in terms of time and money- in science education. According to Kirschner and Huisman (1998), non-laboratory practicals ('dry labs') such as computer-based simulations are well suited to help students acquire specific cognitive skills (such as analysis, synthesis and evaluation) needed to practice science and to carry out scientific inquiry. The principal sub-skills for independent scientific work that can be developed through practical work are: discrimination, observation, measurement, 
estimation, manipulation, planning, execution and interpretation. In order to gain these skills, extensive practice in dealing with problems and frequent feedback as to whether the approaches used and solutions determined are successful are essential. Due to the technological advances it is no longer necessary for students to learn from costly, laboratory, practicals, instead, they can learn from computer-based simulations in an effective, efficient and safe way. Troubleshooting simulations, the vehicle used within this study to help students acquire complex cognitive skills, are especially well suited to this because they allow students to develop and follow (often poor) solutions and designs and then to discover, modify and eliminate their inadequacies quickly and safely.

Woolnough (1983) goes so far as to call this use of practicals "investigations" since natural scientists are investigators and problem-solvers. Their method of working entails a cyclical process involving:

- studying a situation and acknowledging that there is actually a problem to be solved

- defining the problem to be solved

- seeking alternative solutions/solution strategies for the problem

- evaluating the alternative solutions/solution strategies

- specifying or choosing the 'best' solution strategy

- solving the problem

- evaluating the solution and determining whether a new problem need be acknowledged, in which case the cycle begins again

Common sense tells us that, in order to acquire a complex skill, traditional (expository) substantive information is a prerequisite for this. Before one can do something with this information (act upon it, act with it), one first has to internalise it. Each step in the process above presupposes the possession of information, including knowledge of methods and techniques, knowledge of one's own domain (theories, principles, concepts and facts) and 
of related domains. In simple terms, one must acquire a broad critical knowledge of the subject matter, the learning of basic competencies, prior to successful, productive and useful scientific enquiry. Subsequently, one can learn to synthesise concepts rationally, enquire scientifically and solve problems via unrestrained inductive thinking (Kyle, 1980).

After having internalised the necessary substantive information, students need to be placed in situations where they have to make use of that information in carrying out the tasks associated with scientific inquiry. Practicals provide an opportunity to develop complex skills, such as investigating and problem solving. This is especially the case for science simulations where quick, easy, and safe repetition of experiments (in our case malfunctioning electrical circuits) is possible. In other words, it assists them in refining their understanding of: problem identification; experimental design; assembling, testing and calibrating equipment; data collection; analysis; interpretation; and reporting of results. The major problem is how to design such computer-based practicals so that the necessary substantive information is presented just in time in order to help the students to acquire the necessary complex cognitive skills optimally effective and efficient.

Real learning is based upon a network of interrelated, often heterarchically organized competencies (here troubleshooting of electrical circuits). These competencies subsume, in turn, nested networks of knowledge (e.g., what a short circuit is), skills (e.g., how an ammeter is attached), and attitude (e.g., that there can be more than one right answer). These knowledge, skills and attitudes require learning settings in which the knowledge can be gained and the skills and attitudes can be acquired in authentic, meaningful contexts. These modern curricula make use of design principles based upon constructivism to achieve this (Kirschner, 2000). Constructivism is neither an approach to nor a model for instructional design. It is a philosophy of learning based on the idea that knowledge is constructed by learners - and eventually 'the one(s) who know(s)' - based on their mental and social activity. 
Learners are active in seeking meaning. Consistent with this view, learning must be situated in a rich context (Brown, Collins \& Duguid, 1988), reflective of real world contexts, for this constructive process to occur and for transfer to environments beyond the school to be possible. The tasks must be authentic and are best learnt through cognitive apprenticeship (Collins, 1988) on the part of the learner in a rich environment. Finally, all of this is best (and possibly only) achieved when learning takes place via poorly or in ill-structured problems (Spiro, Coulson, Feltovich \& Anderson, 1988).

And, when should the substantive necessary information within the domain be presented? In other words, when is it 'just in time'? Is there a difference between more general information needed for troubleshooting a problem and more task-specific, procedural information? If the information necessary to solve the troubleshooting problem is not presented at the right time so that there is a distinct coupling between the perception of the necessary information and the actions taken (Gibson, 1977), the expected benefits might not be achieved.

Complex skills contain two types of constituent skills or sub skills, which are different in nature, namely, variable constituent skills and consistent constituent skills (Fisk and Gallini, 1989; van Merriënboer, 1997). Variable skills are steered by the interpretation of cognitive schemata and their performance varies from task situation to task situation (i.e. other use of the same, general knowledge); consistent skills are directly driven by the application of cognitive rules or automated schemata and their performance is virtually the same in every task situation (i.e. same use of the same, situation-specific knowledge). For example, a computer programmer not only has to master a programming language (e.g. consistent skills such as writing an IF-THEN statement in computer code) but also the skill of making a technical design for an application (e.g. variable skills such as drawing a NassiShneidermann diagram for a specific computer program). The usage of an IF-THEN 
statement in a specific computer program is always the same and always leads to the same result, but, although the technique of drawing a Nassi-Shneidermann is always the same, its application depends on the specifications of a computer program and always leads to other results. The same occurs in the subject of this study, namely troubleshooting electrical circuits. In order to find the problems in a malfunctioning electrical circuit and to repair them, a task performer not only has to be able to properly insert the specific elements (e.g. consistent skills such as inserting a voltmeter in parallel because current cannot flow through this meter), but also has to be able to understand conditions that influence current and current intensity (e.g. variable skills such as the difference between a series connection and a parallel connection and their influence on the circuit). The usage of a voltmeter is always the same and always leads to the same result (i.e. measurement of voltage through the circuit), but, although the principles of series and parallel connections are always the same, the features of specific series or parallel connections determine their influence on current and current intensity in the circuit and therefore the results are always different. The exit-behaviour that has to be achieved by mastering variable and consistent constituent skills is also different in nature, just as the processes that lead to this achievement. Mastering variable skills requires the deliberate construction of general, abstract schemata in long-term memory while mastering consistent skills requires the automation of schemata through repetitive practice.

Schema construction is mainly achieved by elaboration, that is, the gradual integration and anchoring of new information in already existing cognitive structures in long-term memory (Mayer, 1980). Schema automation is mainly accomplished by proceduralisation (Anderson, 1982; Anderson, 1996), in which factual information is embedded in so-called productions (i.e. primitive rules that drive cognitive action). Proceduralisation only occurs when all necessary information to carry out the training task is available in working memory at the time the task is practiced. Different types of information are needed for schema 
construction and automation to occur. The information associated with schema construction is called supportive information and consists of mental models of how a learning domain is organized, for example, knowledge about the structure of electrical circuits, the working of series connections and differences between series connections and parallel connections. The information needed to achieve schema automation is called procedural information and consists of task-specific rules that specify actions to achieve particular goals and the facts, principles and concepts that are needed to correctly apply the task-specific rule (e.g. an ammeter has to be connected in series (the task-specific rule) because this meter has no resistance (the underlying principle); more examples of these information types can be found in the Appendix which gives an impression of the supportive and procedural information used in this study). Coming back to the demand-pull principle, Kester, Kirschner and van Merriënboer (2001) argue that the mastery of a complex skill requires supportive information before practice to allow for the construction of schemata and elaboration of mental models, in combination with procedural information during practice to allow for the automation of schemata and proceduralisation of task-specific rules. This assumption is supported by guidelines for effective and efficient development of instructional material generated by cognitive load theory (Chandler and Sweller, 1991; Sweller, 1988; Sweller, van Merriënboer and Paas, 1998).

A major pillar of cognitive load theory is the assumption that working memory is severely limited (Baddeley, 1992; Miller, 1956). Since, the acquisition of a complex skill puts a considerable burden on working memory, it is important to attend to the effective management of cognitive load during the acquisition process. One of the most important design principles pertains to the reduction of so-called extraneous cognitive load. Extraneous cognitive load refers to the load that is caused by the instructional material itself and involves all the processes a learner engages in during a task but which are not directly beneficial to 
learning (e.g. searching for relevant information sources, combining different information sources, weak-method problem solving etc.). To this end, extensive research has been carried out concerning the split attention effect (for an overview see Sweller, van Merriënboer and Paas, 1998), whereby that extraneous load is significantly reduced by integrating two mutually referring information sources instead of presenting them separately in either space or time. By physically integrating the necessary information sources in the instructional material, learners do not longer have to mentally integrate the sources themselves, and therefore, extraneous cognitive load is reduced. In this study, the focus is on avoiding temporal split attention. Strictly speaking, to avoid temporal split attention all necessary information to carry out a task (i.e. supportive as well as procedural information) should be presented during task practice, but, simultaneously processing all the necessary information and practicing the tasks can produce cognitive overload if the task itself is already causing a high so-called intrinsic cognitive load (Marcus, Cooper and Sweller, 1996).

This intrinsic cognitive load is determined by the degree of element interactivity within a task (Sweller, van Merriënboer and Paas, 1998). High element interactivity requires the learner to process several elements and their relationships simultaneously in working

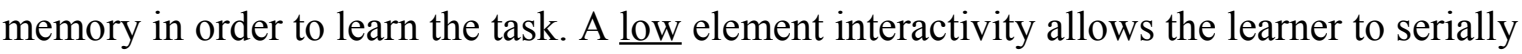
process few elements at a time. Learning supportive information is, in general, a task with high element interactivity because to-be-constructed mental models contain many interrelated elements. For example in this study, the learner has to simultaneously process features of electrical circuits and features of a central heating system to understand the flow of current in an electrical circuit. On the other hand, learning procedural information is, in general, a task with low element interactivity because task-specific rules only contain few related elements. For example, the learner can easily process each symbol that must be used to denote a particular element in an electrical circuit. Based on the idea of avoiding temporal split 
attention and managing intrinsic cognitive load it is advocated that supportive information (i.e. information with a high element interactivity that can easily lead to cognitive overload when presented during practice) is best presented before the learner starts relevant task practice while procedural information (i.e. information with a low element interactivity) is best presented during relevant task practice (van Merriënboer, Kirschner and Kester, in press).

The research presented here attempts to find evidence for an optimal information presentation format based on the demand-pull principle and guidelines from cognitive load theory. The presumed optimal format, that is, supportive information before practice in combination with procedural information during practice, is compared with three alternative formats, namely (1) all information before practice, (2) all information during practice, and (3) procedural information before practice combined with supportive information during practice. The effectiveness of all four information presentation formats, measured by information searching behaviour, practice performance, transfer test performance, time-ontask and invested mental effort, is studied in the domain of physics. It is predicted that learners who receive supportive information before task practice combined with procedural information during task practice will show substantially less information searching behaviour than the other learners. Moreover, for this group a higher performance during practice and during a transfer test and lower invested mental effort is expected than for the other groups. 


\section{Method}

The purpose of this study was to test the hypothesis that the presentation of supportive information before practice, in combination with the presentation of procedural information during practice, reduces searching behaviour and yields higher learning outcomes for students in computer-based physics practicals. All information was presented to the learners on the computer screen of a troubleshooting task in electrical circuits, a typical part of the high school physics curriculum in the Netherlands. A factorial design was used with the factors timing of supportive information (either before or during practice) and timing of procedural information (also either before or during practice).

\section{Participants}

Eighty-eight third year high school students at Sintermeertencollege in Heerlen, the Netherlands ( 37 male, 51 female; mean age $=14$ years, $\underline{\mathrm{SD}}=.52$ ) participated in this study. All of the participants spoke Dutch as their first language, the language in which the instruction was given. They were required by their teacher to participate in a physics simulation course on electrical circuits as part of their regular physics curriculum. No specific grade was given for this course. In the Netherlands, all students in the academic stream in high school receive physics education in their third year. The content used in the physics simulation course was new for all participants. They received 9 euro (approximately 9 dollars) for their participation.

Materials: The physics course.

Crocodile Physics $^{\circledR}$, a simulation program for secondary school science classes, was used to develop the physics course for this experiment. The course contained an introduction and ten practice troubleshooting tasks for faulty electrical circuits and was followed by ten test tasks. In the introduction the participants received information on: 
what to expect, e.g. the number of problems, available time and how to switch the circuit on and off;

- how to navigate within the application, e.g. left and right arrows were used to go back or forth in the course, by clicking on different icons participants could jump to an information block, a practice problem or a test problem; and

- the experimental rules, e.g. changing the circuit itself (e.g. removing a lamp or rewiring the circuit), taking notes or changing the computers configuration (e.g. change the full screen presentation to part screen, making changes in the menu of Crocodile Physics ${ }^{\circledR}$ ) was not allowed, and that the work had to be done individually and independently. The troubleshooting tasks, consisting of malfunctioning electrical circuits, were accompanied by information blocks presented either before practice, during practice or before and during practice. Every problem was presented in a split screen with on the left, if applicable, an information block and on the right the malfunctioning circuit (see figure 1). Inherent to a malfunctioning circuit is that elements (e.g. lamps) become irreversibly damaged after one try (i.e. it explodes). So, to allow the participants a good look at what happens in a circuit when certain actions are performed each circuit was presented twice. Participants had to explain what the problem was and how this problem could be solved. The circuits in the practice tasks made use of a maximum of six elements: a toggle switch, a lamp, a battery, a resistor, a voltmeter and an ammeter. The tasks differed in the number of elements used and the number of different elements used.

In cooperation with a subject matter expert, a task analysis was carried out to determine which information needed for the troubleshooting tasks was supportive and which was procedural. Information that either aimed at schema construction, had a high element interactivity and was not referring directly to the circuits in the troubleshooting tasks was labelled as supportive. An example of this is the explanation of how current flows through a 
closed electrical circuit using a central heating system as an analogy. Information that aimed at schema automation, had a low element interactivity and referred directly to the circuits in the troubleshooting tasks was labelled as procedural. An example of this is the text 'This is a voltmeter and electrical potential is measured by a voltmeter' next to the symbol for a voltmeter. An impression of the supportive and procedural information used in this study is given in the Appendix.

Information presentation. Four information presentation formats were distinguished. The participants were randomly assigned to one of these formats. In the SupB-ProcB format, both supportive (Sup) and procedural (Proc) information were presented before (B) the participants practiced the troubleshooting tasks $(\underline{\mathrm{n}}=22)$. The participants assigned to the SupD-ProcD format received both information types during (D) the troubleshooting of the practice circuits $(\underline{\underline{n}}=22)$. In the SupB-ProcD format, predicted to be optimal, supportive information was presented before task practice and procedural information was presented during task practice $(\underline{\mathrm{n}}=23)$. In the SupD-ProcB format the supportive information was presented during task practice while the procedural information was presented before the participants practiced the troubleshooting tasks $(\underline{\mathrm{n}}=21)$.

Log tool. A logging program was especially developed for the experiment. This program kept track of the time on task and of the navigation of the participants through the physics course. A screen dump was made and saved every time the participants opened a new window. Each collection of screen prints shows the route that the participants followed through the course.

Practice problems. During practice, the participants could obtain a maximum of 49 points by diagnosing and finding solutions to the malfunctioning circuits in ten practice tasks. For every correct statement made, they received one point. For example, the situation in figure 1 is that, when the switch is closed, the lamp explodes. In this task the following 
statements were rewarded with one point: the lamp explodes, the power supply (i.e. the battery) is too strong, insert a weaker battery, insert an extra lamp or insert a resistor. The maximum number of points the participants could receive for the practice tasks ranged from four to eight. In the given example it is five, the problem statement (i.e. the lamp explodes), the reason for the problem (i.e. the power supply is too strong) and three possible solutions (i.e. insert a weaker battery, an extra lamp or a resistor). The practice performance scores of ten participants were determined by two raters. The interrater reliability for practice performance of the two raters was 0.96 (Intraclass Correlation Coefficient, SPSS) and the internal consistency is 0.72 (Cronbach's alpha).

\section{[Insert figure 1 about here]}

Transfer test. After the ten troubleshooting practice tasks the participants solved ten troubleshooting test tasks. The test tasks also consisted of malfunctioning electrical circuits designed in Crocodile Physics ${ }^{\circledR}$ but without the accompanying information blocks. Five of the test problems were equivalent to the practice tasks and five contained new elements (i.e. a variable resistor, a fuse, a push switch, a buzzer, a LED, or a motor and gears). Participants again had to explain what the problem was and how it could be solved. The transfer test was meant to determine whether the participants could perform the learned procedures and whether they were capable of applying these procedures to new situations (i.e. to circuits in which new elements were used). The participants could obtain a maximum of 36 points. As was the case in practice, they received one point for each correct statement, either a diagnosis or a solution. The maximum number of points the participants could receive for the test tasks ranged from one to six. These scores depended on the number of possible solutions that could be given to stop the circuit from malfunctioning. The test performance scores of ten participants were determined by two raters. The interrater reliability for test performance of 
the two raters was 0.85 (Intraclass Correlation Coefficient, SPSS) and the internal consistency of the transfer test was 0.69 (Cronbach's alpha).

Mental effort measurement. Mental effort was measured both during practice and during the test with a 9-point rating-scale (Paas, 1992; Paas, Van Merriënboer and Adam, 1994), which asked the participant to rate their invested mental effort. The mental effort measures ranged from very, very low mental effort to very, very high mental effort. The aim of this mental effort measurement was to get insight in the mental load perceived by the participants while working on the troubleshooting tasks. The rating-scale was administered during practice and during the test directly after each troubleshooting task. Participants were asked: How much mental effort did you invest to repair the former circuit? No additional information was provided to explain the term 'mental effort'. This resulted in a total of twenty mental effort measurements, ten during practice and ten during the test. The internal consistency of the mental effort measures was 0.85 (Cronbach's alpha) for the practice tasks and 0.89 for the test tasks.

\section{Procedure}

Participants received an oral instruction, which stressed that they had to work independently, mind the time limit, work seriously and not ask questions during the experiment. They were told that the aim of the experiment was to find out if it is useful to integrate this kind of simulation software in regular education and, if this is the case, how this should be done.

All participants had two hours to complete the course with the practice tasks and the test tasks. Within these two hours the participants could go through the course and the test at their own pace. Participants could not go back to the practice tasks after they had started the test tasks. During each part, the searching behaviour (in particular, revisiting earlier presented information blocks) and the time spent on each task was logged. 


\section{Results}

\section{Information searching behaviour}

The information searching behaviour of the participants was represented by the number of times a participant consulted the 'before' information block during practice. The SupD-ProcD format is omitted because participants in this group received all of the information during practice, i.e. there was no 'before' information block that could be consulted during practice. Per information presentation format and per practice problem the mean number of times a participant consulted the 'before' information block was calculated. Results are shown in figure 2.

\section{[Insert figure 2 about here]}

An overall mean score was calculated for the number of times the participants consulted the 'before' information block during all practice problems (see table 1).

[Insert table 1 about here]

A Kruskal-Wallis test was used to compare the SupB- ProcB, the SupB- ProcD and the SupD- ProcB format. In this study, an alpha level of 0.05 was used for all statistical tests. A significant difference was found between the information presentation formats, $\mathrm{H}$ $(2)=17.82, p<0.001$. Figure 2 illustrates that participants in the SupB- ProcD format showed, as predicted, substantially less searching behaviour than the participants in the SupBProcB and SupD- ProcB format. They consulted the 'before' information block substantially less frequently than the other participants who did not differ in searching behaviour.

\section{Time on Task}

In this study it is assumed that the information presentation formats have different effects on time on task, therefore, the time on task during practice (including the 'before' information block) is considered. There is a main effect for the timing of procedural information on time on task during practice, $\underline{\mathrm{F}}(1,81)=4.17, \underline{\mathrm{MSE}}=220.30, \underline{\mathrm{p}}<0.05$; 
$\eta^{2}=0.049$. Participants receiving procedural information before practice spent less time on the practice problems $(\underline{\mathrm{M}}=45.46, \underline{\mathrm{SD}}=14.52)$ than participants receiving this information during practice $(\underline{\mathrm{M}}=52.46, \underline{\mathrm{SD}}=15.98)$.

Also, a significant interaction between the timing of supportive and procedural information was found, $\underline{\mathrm{F}}(1,81)=6.39, \underline{\mathrm{MSE}}=220.30, \underline{\mathrm{p}}<0.05 ; \eta^{2}=0.073$. In post hoc tests, using Tukey's HSD, it was found that only the SupB-ProcB group $(\underline{\mathrm{M}}=40.21, \underline{\mathrm{SD}}=$ $10.61)$ and the SupB-ProcD group significantly differed $(\underline{\mathrm{M}}=54.95, \underline{\mathrm{SD}}=17.91 ; \underline{\mathrm{p}}<0.01)$. For an overview of the results see table 2.

[Insert table 2 about here]

\section{Practice scores}

First, it should be noted that the scores are very low for all conditions. ANOVA revealed neither statistical significant main effects nor interaction effects. Nevertheless, the mean scores are highest for the SupB-ProcD condition and thus point into the predicted direction. Practice scores are presented in table 3.

[Insert table 3 about here]

\section{Transfer test}

ANOVA revealed neither statistical significant main effects nor interaction effects. Overall, transfer test scores are very low and presented in table 4.

\section{[Insert table 4 about here]}

\section{Mental effort}

Not all participants filled in all mental effort scales. Only the data of participants who filled in more than $60 \%$ of the mental effort measures during practice (i.e. six items or more; $\underline{\mathrm{n}}=78$ ) or during the test (i.e. six items or more; $\underline{\mathrm{n}}=77$ ) were used in the mental effort analysis. The Expectation Maximization (EM) approach, available in SPSS Missing Values Analysis, was used to replace the missing values with expected values. 
A main effect for procedural information on the mean mental effort during the practice problems (i.e. ten measures) was found, $\underline{\mathrm{F}}(1,78)=4.51, \underline{\mathrm{MSE}}=5.48, \underline{\mathrm{p}}<0.05 ; \eta^{2}=0.06$. Participants receiving procedural information before practice reported less invested mental effort $(\underline{\mathrm{M}}=5.92, \underline{\mathrm{SD}}=1.02)$ than participants receiving this information during practice $(\underline{\mathrm{M}}=$ $6.47, \underline{\mathrm{SD}}=1.20$ ). In post hoc tests, using Tukey's HSD, it was found that only the SupBProcB group and the SupB-ProcD group $(\mathrm{p}<0.05)$ differed significantly. An ANOVA of the mean mental effort during the test (i.e. ten measures) yielded neither main effects nor interaction effects. For an overview of these results see table 5.

[Insert table 5 about here] 


\section{Discussion}

The ability to solve problems, interpret experimental data, and use knowledge and skills in unfamiliar situations are far and away the most important general objectives for science students to achieve via practicals (Kirschner \& Meester, 1993). The major question that this study attempted to answer is: How can practicals best be designed in particular with regard to information presentation so as to help students achieve these objectives. In this study, evidence is found for the hypothesis that, due to task requirements, learners predominantly need supportive information before task practice and procedural information during task practice. The information searching behaviour of the participants who received supportive information before and procedural during practice was substantially lower than that of the participants who received all information before practice and those who received procedural information before and supportive during practice. This means that the participants who received the right information at the right time consulted earlier given information substantially less often during practice than the participants in the two other relevant formats. Hereby can be concluded that the presumed optimal information presentation format (i.e. supportive information presentation before and procedural information during practice) indeed was optimal compared to the format in which all information was presented before practice and the format in which procedural information was presented before and supportive during practice. A final remark has to be made concerning the format in which all information was presented during practice. Participants in this format were prohibited to show any searching behaviour because no 'before' information block was available in this format. In this study it remains unclear if participants would have shown any searching behaviour if a 'dummy' information block was available to them before practice. Therefore, no conclusions can be drawn with regard to the searching behaviour of participants in the 'all during' format. 
In spite of the apparent optimal information presentation in our preferred format (supportive before, procedural during), no significant effects for this format were found on the effectiveness of the instruction. The performance scores during practice were slightly in favour of the preferred condition but also extremely low, indicating that during the acquisition phase of the complex skill (i.e. troubleshooting electrical circuits) not much was learned. Obviously, this also has its impact on the performance on the test. For transfer test performance no differences were found. In retrospect, the given information and the practice problems seemed to be too difficult for the participants, so, a bottoming effect appeared for the test results. Apparently, the amount of practice offered was not sufficient for acquiring the complex skill of troubleshooting.

With regard to time-on-task and mental effort, it appeared to be more efficient to present procedural information before practice, the effect of which is intensified when supportive information is also presented before practice. Thus, time on task and invested mental effort was lowest when all information was presented before practice. At first sight, these results seem to contradict the assumptions regarding the effectiveness of the instructional material. But the term effective is misleading in this context, because the lower mental effort and shorter time on task are not accompanied by a higher performance during practice or the test. For example, it is well possible that participants who received the procedural information before practice, in comparison to those who received this information during practice, found it more difficult to fully grasp the relevancy of this information, became confused and discouraged by this presentation mode and therefore invested less time and mental effort in the practice problems. In short, given the low overall performance, it is impossible to make a value judgment regarding the time on task and mental effort results.

Nevertheless, another alternative explanation has to be given for the mental effort results. After each malfunctioning circuit the following question was posed: How much 
mental effort did you invest to repair the former circuit? With this question it was intended to measure the mental effort the participants invested in diagnosing and repairing the malfunctioning circuit aided by the presented information. In the format with the lowest mean mental effort score (i.e. all information before), this question only follows the malfunctioning circuit because all the necessary information had already been presented before practice. However, in the other three formats this question directly follows the malfunctioning circuit in combination with an information block. Therefore, it is well possible that the participants in the 'all before' condition failed to take the necessary information into account while giving a mental effort score for diagnosing and repairing the circuit. This could have had an unjust decreasing effect on the mental effort scores for these participants.

Regardless of the bottom effect, the preferred information presentation format, based on the task demand-pull principle, avoiding temporal split attention and managing intrinsic cognitive load, did not fully succeed in optimally equipping the learners for the task at hand. So, why did these facilitating effects fail to occur? It is possible that the avoidance of temporal split attention by presenting procedural information during task practice is of no use when the instructional material still allows for spatial split attention, as was the case in our study. In the presented materials the learners still had to mentally integrate the presented information with the malfunctioning circuit in order to understand what the problem was. This mental integration process could have interfered with the skill acquisition process and vice versa. The beneficial effects of the presentation of supportive information before task practice to manage intrinsic cognitive load may not have surfaced because the introduction did not prepare the learners for the tasks that were about to come and therefore the learners could have missed the relevance of this supportive information completely. Moreover, the presentation of procedural information during task practice could have prevented that the learners consulted the supportive information presented before task practice because, strictly 
speaking, the procedural information is in nature enough to carry out the task, but not nearly enough to reach deeper understanding and schema construction. Although the right information was presented at the right time, simultaneously manipulating the circuit, mentally integrating the necessary information and judging every piece of information on its own merit may have been too challenging for the learners.

Future research is needed to find out which cognitive load managing measures are useful to apply to the timing of information presentation. For example, it seems to be the case that only the avoidance of temporal split attention is no guarantee for a favourable learning outcome. It may be necessary to take temporal and spatial split attention effects into account at the same time. Furthermore, the results of our current study are especially coloured by the low practice and test performance scores; in the future, such an effect should be avoided by simplification of the instructional materials and taking the learners' entry levels more carefully into account. Finally, when different information presentation formats are compared, each format should allow for the same searching activities, there are two possibilities: the usage of 'dummy' information blocks were necessary or prohibition of consulting former information blocks in all formats.

To conclude, the results from this study indicate that it is possible to determine optimal information presentation moments for these types of simulation practicals in science curricula based on task requirements. The distinction between supportive information and procedural information proved to be useful to distinguish between different optimal moments for presentation. When the learners are allowed to search during task practice, they have to search less for necessary information when it is presented according to task demand-pull principles, that is, supportive information just before it is needed for practice and procedural information directly during practice. Unfortunately, performance scores did not yet corroborate this result, which is probably due to a bottom effect. 


\section{References}

Anderson, J. R. (1982). Acquisition of cognitive skill. Psychological Review, 89(4), 369-406.

Anderson, J.R. (1996). ACT: A simple theory of complex cognition. American Psychologist, $51,355-365$.

Baddeley, A. D. (1992). Working memory. Science, 255, 556-559.

Brown, J.S., Collins, A., \& Duguid, P. (1989). Situated Cognition and the culture of learning. Educational Researcher, 18(1), 32-42.

Chandler, P., and Sweller, J. (1991). Cognitive load theory and the format of instruction. Cognition and Instruction, 8, 293-332.

Cheng, T. C. E., and Podolsky, S. (1993). Just-in-time manufacturing. An introduction.(Jarvis, P., Ed.). London: Chapman and Hall.

Collins, A. (1988). Cognitive apprenticeship and instructional technology (Technical Report No. 6899). BBN Labs Inc., Cambridge, MA.

Fisk, A.D., and Gallini, J.K. (1989). Training consistent components of tasks: Developing an instructional system based on automatic-controlled processing principles. Human Factors, 31, 453-463.

Fuchsberg, G. 1990, June 6. Business schools get bad grades. Wall Street Journal. pp. B1-B2. Gallagher, M. (2001). Lifelong learning: Demand and supply issues - some questions for research. Paper presented at: The business/ higher education roundtable conference on the critical importance of lifelong learning. Retrieved April 18, 2002 from the World Wide Web: http://www.detya.gov.au./highered/otherpub/lifelong/default.htm

Gibson, J. J. (1977). The theory of affordances. In R. Shaw \& J. Bransford (Eds.), Perceiving, Acting and Knowing (pp. 67-82). Hillsdale, NJ: Erlbaum. 
Hoyt, B. R. (1996). The just-in-time approach to effectively use business software in college business courses (Report No. IR 018 261). Association of small computer users in education (ASCUE). (ERIC Document Reproduction Service No. ED 405 821)

Kester, L., Kirschner, P. A., van Merriënboer, J. J. G. and Bäumer, A. (2001). Just-in-time information presentation and the acquisition of complex cognitive skills. Computers in human behavior, 17, 373-391.

Kirschner, P.A. (2000). Using integrated electronic learning environments for collabortive teaching/learning. Research Dialogue in Learning and Instruction, 2(1), 1-10.

Kirschner, P.A. \& Huisman, W. (1998). Dry laboratories in science education: Computerbased practical work. International Journal of Science Education, 20(6), 665-682.

Kirschner, P. A., \& Meester, M. A. M. (1993). Learning objectives for science practicals at traditional and distance universities. Distance Education, 14(2), 260-282.

Kyle, W. C. (1980). The distinction between inquiry and scientific inquiry and why high school students should be cognizant of the distinction. Journal of Research on Science Teaching, 17, 123-130.

Marcus, N., Cooper, M., and Sweller, J. (1996). Understanding instructions. Journal of educational psychology, 88(1), 49-63.

Mayer, R. E.. (1980). Elaboration techniques that increase the meaningfulness of technical text: An experimental test of the learning strategy hypothesis. Journal of Educational Psychology, 72, 770-784.

Miller, G. A. (1956). The magical number seven plus or minus two: Some limits on our capacity for processing information. Psychological Review, 63, 81-97.

Openworld (2000). On-demand learning group. Retrieved April 18, 2002 from the World Wide Web: http://www.openworld.com/ondemand/default.htm 
Paas, F. G. W. C. (1992). Training strategies for attaining transfer of problem-solving skill in statistics: a cognitive- load approach. Journal of educational psychology, 84(4), 429434.

Paas, F. G. W. C., van Merriënboer, J. J. G. \& Adam, J. J. (1994). Measurement of cognitive load in instructional research. Perceptual and motor skills, 79, 419-430.

Spiro, R.J., Coulson, R.L., Feltovich, P.J., \& Anderson, D.K. (1988). Cognitive flexibility theory: Advanced knowledge acquisition in ill-structured domains (Tech. Rep. No. 441). Champaign, IL: University of Illinois, Center for the study of reading.

Sweller, J. (1988). Cognitive load during problem solving: Effects on learning. Cognitive Science, 12, 257-285.

Sweller, J., Van Merriënboer, J. J. G., and Paas, F. (1998). Cognitive Architecture and Instructional Design. Educational Psychology Review, 10(3), 251-296.

Van Merriënboer, J.J.G. (1997). Training complex cognitive skills: A four-component instructional design model for technical training. Englewood Cliffs, NJ: Educational Technology Publications.

Van Merriënboer, J. J. G., Kirschner, P. A., and Kester, L. (in press). Taking the load off a learner's mind: instructional design for complex learning. Educational Psychologist. Woolnough, B. E. (1983). Exercises, investigations and experiences. Physics Education, 18, $60-63$. 
Table 1

Summary of the mean revisiting behaviour data.

\begin{tabular}{llllllll}
\hline & \multicolumn{7}{c}{ Supportive information } \\
\hline Procedural information & Before & \multicolumn{5}{c}{ During } \\
Before & $\underline{\mathrm{M}}$ & $\underline{\mathrm{SD}}$ & $\underline{\mathrm{n}}$ & $\underline{\mathrm{M}}$ & $\underline{\mathrm{SD}}$ & $\underline{\mathrm{n}}$ \\
During & 5.86 & 4.64 & 22 & 7.62 & 6.06 & 21 \\
\hline
\end{tabular}


Information presentation and troubleshooting in electrical circuits 28

Table 2

Mean total time (min) spent on the practice problems and the 'before' information block

\begin{tabular}{lllllll}
\hline & \multicolumn{9}{l}{ Supportive information } \\
\cline { 2 - 7 } Pefore & $\underline{\mathrm{S}}$ & $\underline{\mathrm{SD}}$ & $\underline{\mathrm{n}}$ & $\underline{\mathrm{M}}$ & $\underline{\mathrm{SD}}$ & $\underline{\mathrm{n}}$ \\
\cline { 2 - 7 } Procedural information & 40.21 & 10.61 & 22 & 51.53 & 16.28 & 19 \\
Before & 54.95 & 17.91 & 22 & 49.96 & 13.75 & 22 \\
During & &
\end{tabular}


Table 3

Summary of the practice performance data ${ }^{\mathrm{a}}$

\begin{tabular}{lllllll}
\hline & \multicolumn{9}{l}{ Supportive information } \\
\cline { 2 - 7 } Procedural information & $\underline{\text { Before }}$ & $\underline{\mathrm{SD}}$ & $\underline{\mathrm{n}}$ & $\underline{\mathrm{M}}$ & $\underline{\mathrm{SD}}$ & $\underline{\mathrm{n}}$ \\
\cline { 2 - 7 } & 7.50 & 3.42 & 22 & 7.10 & 4.62 & 21 \\
\hline Before & 8.52 & 5.07 & 23 & 7.32 & 5.19 & 22 \\
During & & & & &
\end{tabular}


Table 4

$\underline{\text { Summary of the transfer test data }}$

\begin{tabular}{lllllll}
\hline & \multicolumn{9}{l}{ Supportive information } \\
\cline { 2 - 7 } Procedural information & $\underline{\text { Before }}$ & $\underline{\mathrm{SD}}$ & $\underline{\mathrm{n}}$ & $\underline{\mathrm{M}}$ & $\underline{\mathrm{SD}}$ & $\underline{\mathrm{n}}$ \\
\cline { 2 - 7 } & 7.14 & 3.82 & 22 & 6.43 & 3.63 & 21 \\
\hline Before & 6.04 & 4.51 & 23 & 5.77 & 3.87 & 22 \\
During & & & & &
\end{tabular}


Table 5

$\underline{\text { Summary of the mean mental effort data during practice and transfer test }{ }^{\mathrm{a}}}$

\begin{tabular}{|c|c|c|c|c|c|c|}
\hline \multirow[b]{3}{*}{ Procedural information } & \multicolumn{6}{|c|}{ Supportive information } \\
\hline & \multicolumn{3}{|c|}{ Before } & \multicolumn{3}{|c|}{ During } \\
\hline & $\underline{\underline{\mathrm{M}}}$ & $\underline{\mathrm{SD}}$ & $\underline{\mathrm{n}}$ & $\underline{\underline{M}}$ & $\underline{\mathrm{SD}}$ & $\underline{\mathrm{n}}$ \\
\hline \multicolumn{7}{|c|}{ Practice } \\
\hline Before & 5.63 & 1.02 & 21 & 6.26 & 0.95 & 18 \\
\hline During & 6.63 & 1.12 & 19 & 6.32 & 1.29 & 20 \\
\hline \multicolumn{7}{|c|}{ Transfer test } \\
\hline Before & 5.35 & 1.11 & 21 & 5.44 & 0.99 & 17 \\
\hline During & 5.82 & 1.73 & 19 & 5.86 & 1.44 & 20 \\
\hline
\end{tabular}

${ }^{\mathrm{a}} \operatorname{Max}=9$ 
Information presentation and troubleshooting in electrical circuits 32

Figure captions

Figure 1: Screenshot of a practice problem.

Figure 2: Mean information searching behaviour per information presentation format and per practice problem. Sup $=$ supportive, Proc $=$ procedural and $\mathrm{B}=$ before and $\mathrm{D}=$ during. 


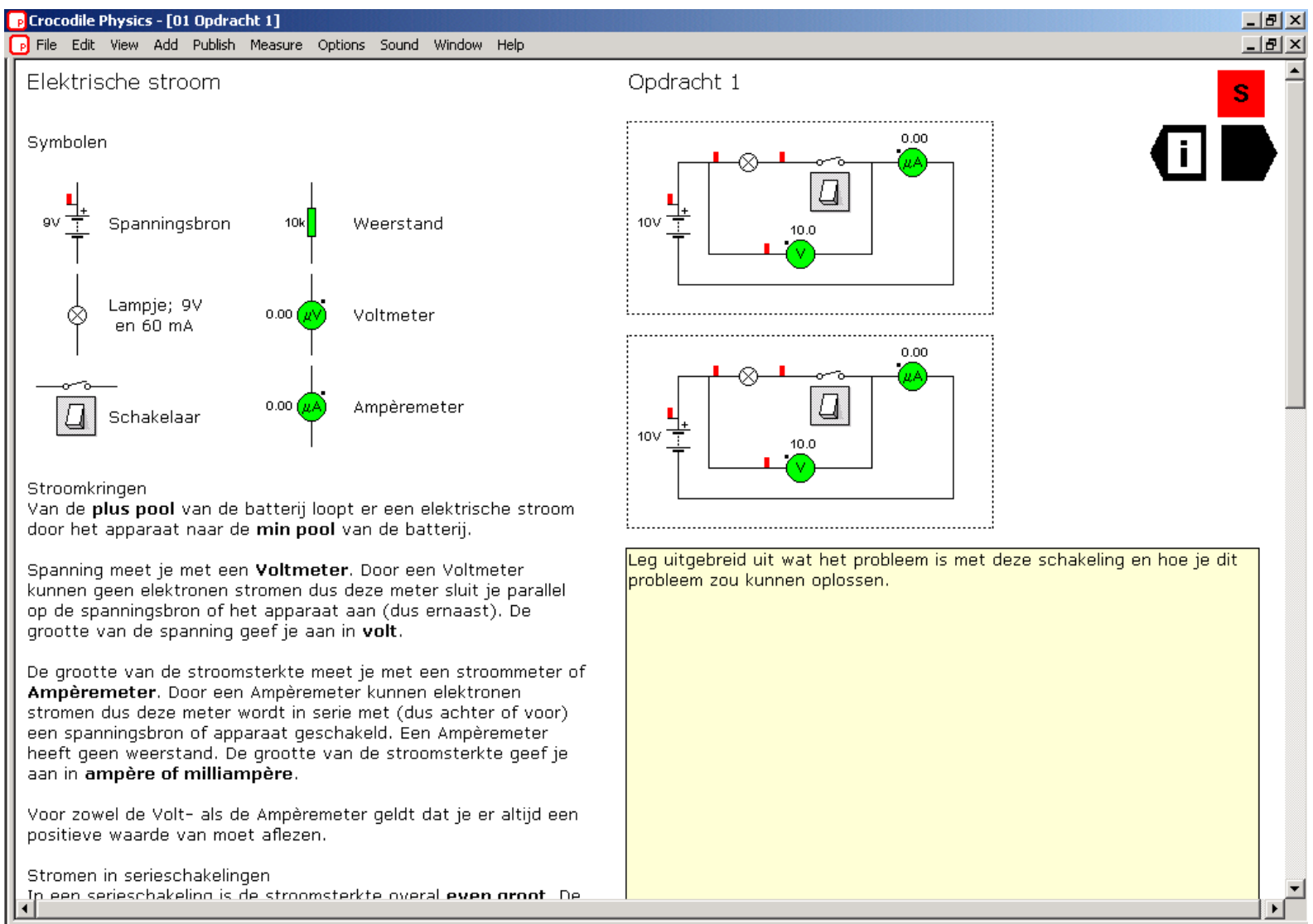




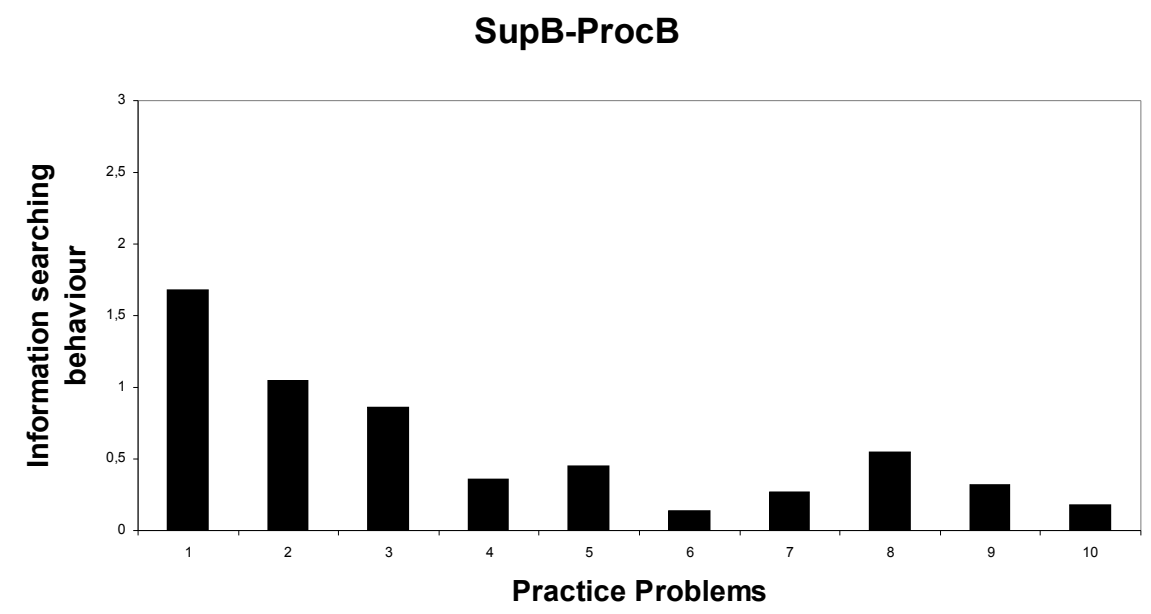

(a)

SupB-ProcD

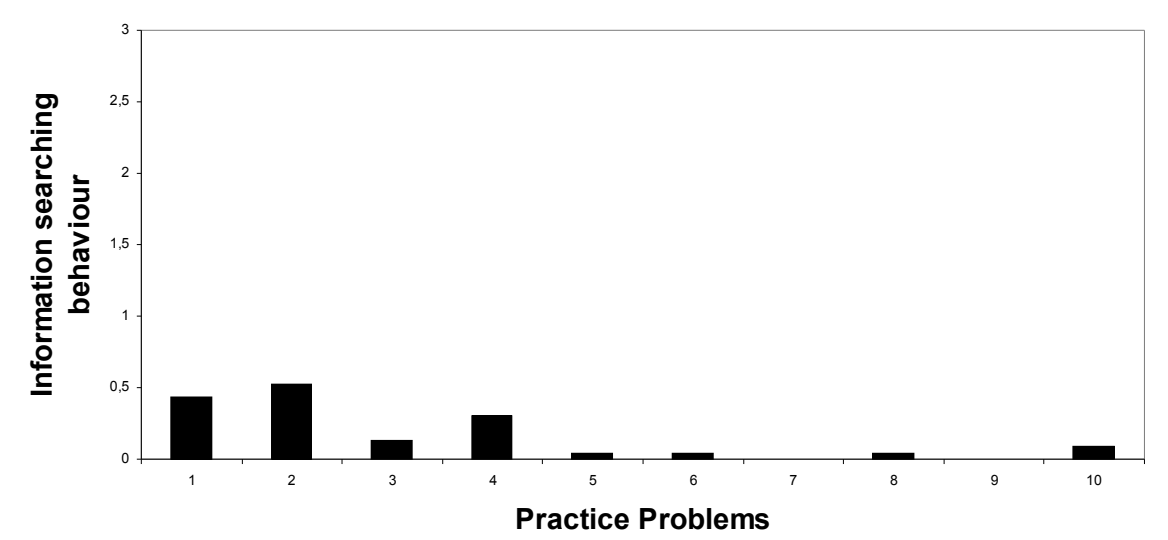

(b)

SupD-ProcB

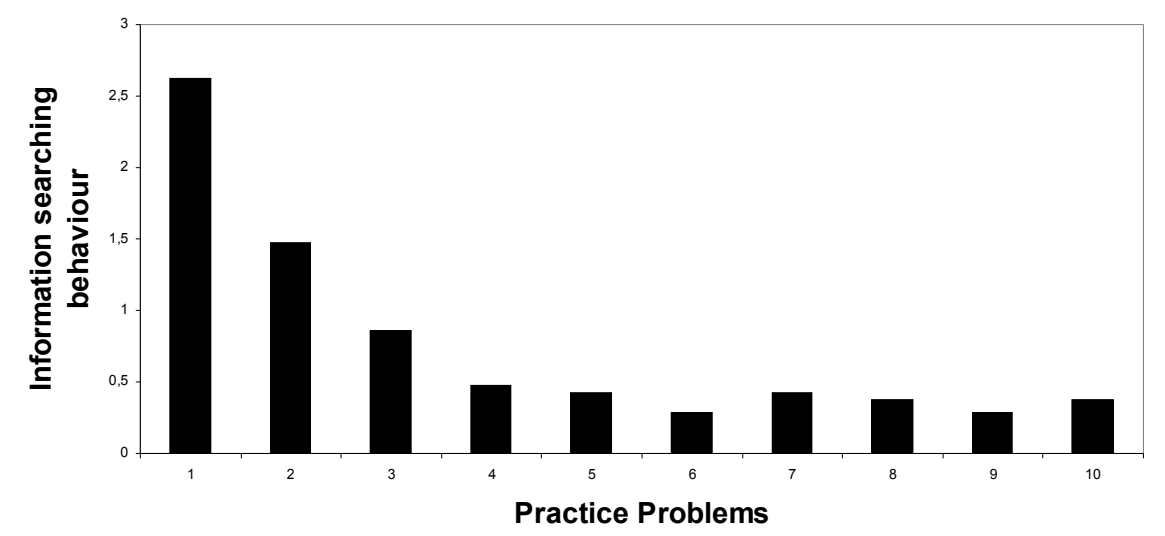

(c) 
Appendix

Impression of the supportive and procedural information used in this study

\begin{tabular}{|c|c|}
\hline Supportive information & Procedural information \\
\hline \multicolumn{2}{|c|}{ Circuits } \\
\hline \multicolumn{2}{|l|}{ The definition and explanation of an electrical } \\
\hline \multirow[t]{2}{*}{$\begin{array}{l}\text { circuit analogous to a central heating system. } \\
\text { General purpose and examples of a source of } \\
\text { electrical potential (e.g. a battery). }\end{array}$} & $\begin{array}{l}\overline{\bar{T}} \text { [Symbol of a source of electrical } \\
\text { potential] Current flows from the positive }\end{array}$ \\
\hline & pole of a battery to the negative pole. \\
\hline \multirow{5}{*}{$\begin{array}{l}\text { General purpose of a switch. } \\
\text { Definition of electrical potential. }\end{array}$} & \\
\hline & (V) [Symbol of a voltmeter] Electrical \\
\hline & potential is measured by a voltmeter. A \\
\hline & voltmeter is connected in parallel because \\
\hline & electrons cannot pass through this meter. \\
\hline \multirow[t]{7}{*}{ Definition of current. } & $\begin{array}{l}\text { Electrical potential is expressed in volts. } \\
\text { (A) - [Symbol of an ammeter] An ammeter }\end{array}$ \\
\hline & measures current. An ammeter is connected in \\
\hline & series because this meter has no resistance. \\
\hline & Current is expressed in amperes or milli- \\
\hline & amperes. \\
\hline & A voltmeter and ammeter should always \\
\hline & display a positive value. \\
\hline \multicolumn{2}{|c|}{ Series circuits } \\
\hline \multirow[t]{5}{*}{ Definition of a series circuit. } & The current in a series circuit is the same at all \\
\hline & points in the circuit. The voltage is divided \\
\hline & over the elements in the circuit. Electrons stop \\
\hline & flowing through the circuit when the series \\
\hline & connection is interrupted. \\
\hline \multicolumn{2}{|c|}{ Parallel circuits } \\
\hline \multirow[t]{6}{*}{ Definition parallel circuit. } & The current in a parallel connection is divided \\
\hline & over the parallel branches. The voltage in a \\
\hline & parallel circuit is the same in every branch. \\
\hline & Interruption of one of the parallel branches \\
\hline & has no consequences for the flow of electrons \\
\hline & through the other branches. \\
\hline \multicolumn{2}{|c|}{ Resistance } \\
\hline
\end{tabular}


Definition and explanation of resistance

analogous to a central heating system and

with car lights as an example.

The higher the resistance in a wire the more

difficulty electrons have flowing through that

wire.

Resistance in series circuits

The more resistors connected in series, the

higher the resistance in the circuit and the

lower the current with a constant voltage.

Resistance in parallel circuits

The more resistors connected in parallel, the

lower the total resistance and the more current

the source of electrical potential delivers. 
Information presentation and troubleshooting in electrical circuits 37

\section{Acknowledgements}

The authors gratefully acknowledge the assistance of Ivo Hamers during the setting up of this experiment and Femke Kirschner and Anne van Piggelen for their help in ordering the raw data. 